Review Article

\title{
METABOLIC AND CLINICAL SIGNIFICANCE OF DIABETES MELLITUS TYPE 2; IMPLICATION FOR RISING PREVALENCE IN NIGERIA
}

\section{Oghagbon E.K.}

Department of Chemical Pathology, Faculty of Basic \& Allied Medical Sciences College of Health Sciences, Benue State University, Makurdi, Nigeria.

*Corresponding Address: Department of Chemical Pathology, Faculty of Basic \& Allied Medical Sciences College of Health Sciences, Benue State University, Makurdi, Nigeria.E-mail: efosaoghagbon@yahoo.com

Received date: April $26^{\text {th }} 2018$, Accepted date: June $3^{\text {rd }} 2018$. Published date: June $30^{\text {th }} 2018$.

\begin{abstract}
Type 2 diabetes mellitus (DM2) is now a global epidemic which is also ravaging developing countries including Nigeria. Its impact in the country is significant with the disease found to impact on hospital admissions, mortality and life expectancy of patients. Previous investigations done in Nigeria showed that DM2 patients have poor glycaemic controls with resultant high levels of disease morbidity and mortality. This was demonstrated by consistently elevated mean HbA1c levels $(>8.0 \%)$ in Nigerian diabetics over a decade of assessment of care of the patients. Similarly the prevalence of diabetic retinopathy rose by more than $200 \%$ between 1989 and 2008 . Diabetic morbidity which is underpinned by hyperglycaemia is associated with diabetic retinopathy, nephropathy, foot ulcers and other clinical conditions such as hyperlipidaemia, altered sympathetic system, bone disorders, infertility, defective body sodium handling and renal compromise. Some investigators believe that persons of African ancestry are more susceptible to some diseases associated with DM2. This includes documented increased renal glomerular hyperfiltration in patients of African ancestry. The disease complications are linked to metabolic derangements which if properly understood and managed, may help to reduce the impact of the rising prevalence of DM2 in Nigeria. Furthermore, if the Nigerian medical team is aware of the peculiar susceptibility of blacks to DM2 complications, they will be able to apply appropriate treatment for improved care, despite rising disease prevalence.
\end{abstract}

Keywords: Clinical significance, Metabolic, Nigeria, Prevalence, Type 2 DM.

\section{Introduction}

Diabetes mellitus type 2 (DM2) is the commonest form of diabetic disease and it accounts for about 90 95\% of the cases in hospital and community. Unlike type 1 diabetes mellitus which is characterised by absolute lack of insulin, DM2 patients have hyperinsulinaemia with relative insulin deficiency. Most patients, especially in the initial period of the disease, have normal or elevated insulin levels. The high concentration of plasma glucose despite raised plasma insulin levels indicates insulin resistance, suggesting a need for increased secretion of insulin by affected individuals in order to suppress elevated endogenous production of glucose, for the establishment of euglycaemia. ${ }^{1}$ The contribution of obesity to DM2 prevalence is significant and it is a major cause of insulin resistance. Due to a delay in diagnosis of DM2 and accompanying gradual development of hyperglycaemia, the patients are at a high risk of vascular (microvascular and macrovasular) complications. The essence of this review is to evaluate and identify peculiar issues of DM2 that pertains to persons of African origin. These are in terms of the disease mechanisms, prevalence and significance of diabetic complications and metabolic findings. It is particularly expected that at the end of this work, readers would have learnt specific pathophysiologic mechanisms that links the black patient to certain commoner complications and how to ameliorate them. 


\section{Epidemiology of Diabetes Mellitus}

Diabetes mellitus is the commonest endocrine disorder affecting almost $6 \%$ of the world's population. ${ }^{2,3}$ The disease is now a global emergency that requires innovative public health and clinical management strategies in order to mitigate the projected increase in disease prevalence, morbidity and mortality. ${ }^{2,3}$ The World Health Organisation estimates that hyperglycaemia is the third highest risk factor for premature mortality, after hypertension and tobacco use. ${ }^{4}$ Over the past few decades, there has been a significant increase in the prevalence of DM in some regions of the world, hitherto with low levels. This has contributed significantly to the negative impact of the disease on the quality of health services in countries such as Nigeria ${ }^{5}$ and Mexico. ${ }^{6}$

\section{Global and Local Projections of Diabetes Mellitus Prevalence}

In 2001, the International Diabetes Federation ${ }^{7}$ predicted that the number of diabetic patients would reach 300 million in 2025 with more than $97 \%$ of them having type II diabetes. ${ }^{8}$ Over the years, various predictions of DM prevalence and projections, ${ }^{9,10,11}$ have underestimated the global burden of this disease. Wild et al, 2004 predicted that the global burden of DM will increase from 171 million in year 2000 to 366 million by 2030 , but this has been shown by $\mathrm{IDF}^{12}$ to be surpassed at 382 million people affected in 2013. A report by IDF in 2013 projects that the number of those affected by DM will be up to 600 million by $2035 .{ }^{12}$ The increasing prevalence of diabetes is now predicted to continue to rise for the next 4 decades by some authors ${ }^{13}$ and thus will have significant impact on life expectancy ${ }^{5,14}$ as a result of increase in disease mortality. ${ }^{14}$

Available evidence shows that the global prevalence of DM has been rising since 1980 till 2014 when it was globally assessed in a study involving over 4 million people. ${ }^{3}$ During this study period, the number of global deaths secondary to diabetes increased by almost $400 \%$. Consequent upon this huge impact of diabetes on mortality, morbidity and health systems cost, especially in developing countries, there is an urgent need for population-based interventions in the fight against the disease. ${ }^{3}$ Such a population-based approach in the evaluation and treatment options for DM will enhance early disease detection and possibly identify pharmacological interventions suitable for prevention or delay disease progress in affected populations. $^{3}$

The increase in DM prevalence is due to rising number of new cases of the disease which is driven by, amongst other factors, a high prevalence of obesity, an ageing population and lack of exercise. ${ }^{14}$ Obesity is a major factor responsible for the increasing prevalence of DM2 in different populations including those in developing countries. ${ }^{4}$ Recently, it has been shown via epigenome-wide association study that adiposity is linked to widespread changes in DNA methylation. Alteration in the DNA methylation is now thought to predict future development of DM2, thus making obesity a major contributor to the rising global prevalence of DM2. ${ }^{15}$ The public health burden of DM in developing countries is worrisome as about $80 \%$ of the global disease burden is borne by those living in such countries. ${ }^{16}$ According to the report by IDF, ${ }^{12}$ the total number of persons affected by DM in Africa will increase by $109 \% ; 19.8$ million in 2013 to 41.4 million in 2035. This projected increase in Africa is the highest for all the regions compared, and is about 5 times the 22\% increase anticipated for Europe over the same period. ${ }^{12}$

In 2000, the IDF report quoted a gross prevalence for adult DM in Nigeria to be $0.4 \%$, but by 2014 the figure increased to $4.6 \% .^{17}$ At this rate Nigeria presently has a diabetic population of 3.8 million people and it is the highest on the Africa continent. ${ }^{17}$ These facts are of concern to health care workers in the country as there could be a proportionate burden of DM2 complications in the coming decades, unless the integrated approach suggested by Zimmet et al, 2014 is applied. ${ }^{16}$ The integrated approach involves understanding all factors related to the pathogenic mechanisms of DM2 in different populations. Otherwise, astronomic increases in diabetic populations will strain the capabilities of the already strained healthcare institutions in developing countries like Nigeria, ${ }^{5}$ thus worsening non-communicable disease death rates. ${ }^{13}$ The authors of this review are of the opinion that integrated approach, beyond understanding the pathogenic mechanisms, should involve appreciation of the metabolic processes underlying the disease complications. Some significant clinical metabolic conditions of DM2 include electrolyte disorders, lipid disorders, defective body sodium handling, hypertension, altered sympathetic nervous system, disorder of infertility, bone disorders, diabetic neuropathy and dementia. 
These disorders are discussed in later sections of this review.

\section{Status of glycaemic control in Nigerian type 2 Diabetes Mellitus patients and its implications}

An earlier study that evaluated glycaemic control over a decade using HbA1c in Nigeria found no significant improvement in glycaemia among Nigerian diabetics of different regions. ${ }^{18}$ This study noted that HbAlc concentration in Ilorin, Nigeria in 2003 was $8.1 \% \pm$ 1.4, and similar studies in 2012 found similar $\mathrm{HbA} 1 \mathrm{c}$ concentration of $8.2 \% \pm 2.2$ in Edo State Nigeria ${ }^{18,20}$ and $8.3 \% \pm 2.2$ in a multi-centre study involving 7 teaching hospitals in the country. ${ }^{18,19}$ These results suggest a widespread poor glycaemia among diabetic patients in the country. The HbA1cstudies mentioned above also showed that over $60 \%$ of the diabetics had mean $\mathrm{HbA} 1 \mathrm{c} \geq 7.0 \%$ indicating poor glycaemic control. ${ }^{19,20}$

Persistent long term poor glycaemic control in Nigeria diabetics is responsible for increasing burden of diabetic complications such as diabetic retinopathy in the patients. ${ }^{21,22,23}$ Evaluation of the studies showed an increase of 200 to $300 \%$ in the prevalence of diabetic retinopathy in Nigerian diabetes mellitus patients, in less than 25 years i.e. 1989-2008 (See Table 1). Some investigators believe this increase could be because Africans are more susceptible to developing diabetic retinopathy compared to other races, even with comparable disease duration. ${ }^{24}$ If this is true, Nigeria clinicians should pay more attention to better understanding of the biology of the disease so as to improve its overall management, especially managing disease complications. This suggestion is emphasised by DM burden on the health care systems in Nigeria. A Nigerian study found that $15 \%$ of admissions in a Nigeria tertiary hospital were due to diabetes mellitus ${ }^{25}$ and $15 \%$ of admitted diabetics in another study had foot ulcers that will result in amputation in about $30 \%$ of them. ${ }^{26}$

The rising prevalence of diabetes mellitus ${ }^{2,3,7}$ and associated complications ${ }^{18,19,20,21}$ indicated above in Nigeria, may impact negatively on the quality of life and longevity of patients. Furthermore, it will put a lot of strain on health care funds, personnel and other resources thereby negatively affecting health services quality in Nigeria.
Table 1: Studies showing changes in prevalence of retinopathy as an index of diabetic complications in Nigeria. ${ }^{18}$

\begin{tabular}{|c|c|}
\hline Studies & \% Retinopathy \\
\hline $\begin{array}{l}\text { Erasmus RT et al. East Afr Med J. 1989; 66: } \\
\text { 248-254. }{ }^{21}\end{array}$ & 15.1 \\
\hline $\begin{array}{l}\text { Rotimi C et al. Ethn Dis. 2003; 13(Suppl.2): } \\
\text { S110-S117. }{ }^{22}\end{array}$ & 24.0 \\
\hline $\begin{array}{l}\text { Ashaye A et al. ClinOphthalmol. Mar } \\
\text { 2008;2(1): } 103-108 .{ }^{23}\end{array}$ & 42.1 \\
\hline $\begin{array}{l}\text { Chinenye } S \text { et al. Indian J EndocrinolMetab. } \\
\text { 2012; 16(4): 558-564. }{ }^{19}\end{array}$ & 35.5 \\
\hline $\begin{array}{l}\%=\text { percentage. Note the increase in prevalence } \\
\text { populations of Nigerian diabetics from } 15.1 \% \text { in } \\
42.1 \% \text { in } 2008 . \text { This represents an increase of } 18 \\
\text { of retinopathy over } 20 \text { years. }\end{array}$ & $\begin{array}{l}\text { of retinopathy in } \\
989 \text { to a peak of } \\
\% \text { in prevalence }\end{array}$ \\
\hline
\end{tabular}

\section{Implications of ineffective management of Diabetes risk factors}

Clearly, both microvascular and macrovascular complications of DM are related to level of dysglycaemia. The high mean level of HbA1c in our diabetic population ${ }^{19,27,20}$ and associated complications such as diabetic retinopathy, ${ }^{19,21,22,23}$ nephropathy ${ }^{19}$ and diabetic foot ulcers ${ }^{26}$ are established facts. These complications are usually associated with long standing hyperglycaemia and poor quality of care of DM patients.

Beyond hyperglycaemia, ${ }^{28}$ hypertension $^{26}$ hyperlipidaema $^{29,30}$ and obesity, ${ }^{31}$ are common in DM2 patients, and these conditions increase the risk of diabetic retinopathy. A Nigeria multicentre study of diabetics ${ }^{19}$ found that only $11 \%$ of the hypertensive diabetics had good blood pressure control. This may explain why high blood pressure has been found to be a major contributor to stroke mortality in diabetic patients in Nigeria. ${ }^{32}$ Hypertriglyceridaemia in particular has been emphasised to be addressed in Nigerian diabetics. ${ }^{33}$ Apart from contributing to retinopathy and other complications of DM, hypertension and hypelipidaemia contributes significantly to observed increase in mortality among diabetics in Nigeria hospital. ${ }^{32}$ Efforts should be made to increase treatment compliance by patients and adherence to treatment guidelines by doctors in the management of these patients. ${ }^{34}$ These measures can help ameliorate risk factors that are known to worsen glycaemia and its complications in DM patients.

The high prevalence of overweight and obesity in Nigeria diabetics, especially among female patients 27,35 is another factor needing attention, as they contributes to worsening $\mathrm{HbA} 1 \mathrm{C}$ over time in our 
patients. $^{20,27}$ In a previous study, we discussed management strategy of obese diabetes patients and identified strategies that can help to improve glycaemia and outcome of the patients. ${ }^{35}$

\section{Some metabolic \& clinical significance of DM2}

Type $2 \mathrm{DM}$ is commonly associated with clinical manifestation of hyperglycaemia and disordered metabolism of fats and proteins. ${ }^{36}$ The clinicmetabolic parameters that underpins the pathognomonic features of DM2 includes, $\beta$-cell dysfunction, hyperinsulinaemia, reduced peripheral utilisation of glucose, increased hepatic and renal glucose production, and elevated plasma levels of non-esterified fatty acids. Added to the above, a primary derangement (insulin resistance) found in the early stages of DM2 is the presence of defective or ineffective translocation of GLUT-4 proteins from cytoplasmic to plasma membrane location. ${ }^{37}$ This is in addition to concomitant elevation of counterregulatory hormones (glucagon, catecholamines, cortisol, and growth hormone). These hormonal alterations are responsible for the increase in hepatic and renal glucose production, and impaired glucose utilization in peripheral tissues. $^{38}$

Figure 1.0 shows the various actions of insulin which include lipogenesis (antilipolysis) and increased glucose utilisation. These insulin functions are impaired in DM2. The combination of insulin insufficiency/deficiency and increased counterregulatory hormones in diabetes, leads to increased lipolysis and release of free fatty acids from adipose tissue to the plasma circulation. The increased plasma NEFAs is associated with pancreatic lipotoxicity and the characteristic $\beta$-cell defect found in some cases of IGT and early stages of DM2. ${ }^{39}$

Metabolic events associated with IGT and DM2 have varied clinical manifestations; electrolyte disorders, lipid and vascular diseases, hypertension, muscle disorders, bone disorders and infertility, dementia amongst others. The elevated level of insulin in the early stages of DM2 subjects may not be effective in driving peripheral glucose metabolism, but is able to enhance other insulin mediated pathways. This has been observed in the sequential activation of Shc, Ras, Raf, and extracellular signal-regulated kinase mitogen-activated protein kinase (MAPK) by hyperinsulinaemia, inmitogenic pathway. ${ }^{40}$ Enhanced mitogenesis under the influence of elevated insulin levels leads to growth of the cells, of vascular smooth muscle, endothelial, and skeletal muscle. ${ }^{40}$ These actions of insulin on vascular smooth muscle cells and endothelium impacts on the progression of cardiovascular diseases in affected patients. ${ }^{41}$

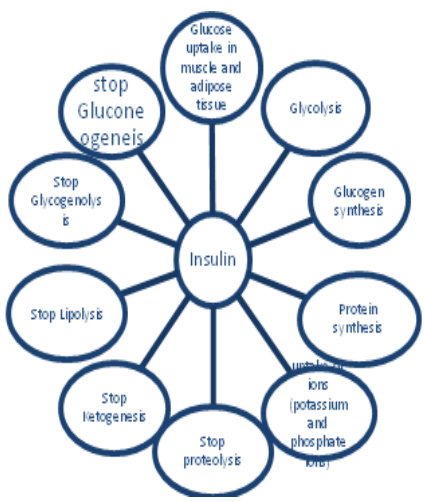

Figure 1.0 Actions of insulin on carbohydrates, fats and proteins in normal and pathophysiological states.

This diagram shows the various actions of insulin in the healthy state; reduction of plasma glucose, fatty acids, increased liver storage of carbohydrate (glycogen) and adipose tissue fat storage. Insulin also decrease breakdown of proteins. These various actions are affected in insulin disorders and they underlie the various clinical and biochemical findings of defective insulin actions.

Below are some of the metabolic processes and clinical conditions associated with DM2 that should be considered in Nigerian DM2 subjects.

\section{Electrolyte disorders}

Hyponatraemia is a common disorder in Diabetes mellitus. The disorder is independent of drugs or hyperglycaemia associated with the disease,${ }^{42}$ but has been linked to increased frequency of impaired renal function, malabsorption syndrome, acid-base disorders and multidrug use, in affected patients. ${ }^{43}$ Hyperglycaemia is known to increase serum osmolality which leads to diffusion of water from the intracellular space to the plasma thus resulting in haemodilution and hyponatraemia. In addition, improperly managed DM induces hypovolemichyponatremia due to osmotic diuresis. Particularly in diabetic ketoacidosis, ketone bodies ( $\beta$ hydroxybutyrate and acetoacetate) cause urinary electrolyte losses thus aggravating renal sodium wasting. ${ }^{44}$ Defective insulin metabolism is also associated with loss of body potassium. The mechanisms linked to hypokalaemia in diabetics include: (1) redistribution of potassium $\left(\mathrm{K}^{+}\right)$from the 
extracellular to the intracellular fluid compartment, especially due to exogenous insulin, (2) gastrointestinal loss of $\mathrm{K}^{+}$due to malabsorption syndromes in diabetes-induced motility disorders, and (3) renal loss of $\mathrm{K}^{+}$(due to osmotic diuresis and/or coexistent hypomagnesaemia). Hypomagnesaemia induced hypokalaemia occurs as a result of intracellular hypomagnesaemia $\left(\mathrm{Mg}^{2+}\right)$ induced activation of the renal outer medullary $\mathrm{K}^{+}$channel loss of $\mathrm{K}^{+}{ }^{45}$ On the other hand, the occurrence of chronic hyperkalemia, in some diabetics, is due to hyporeninemic hypoaldosteronism syndrome. The condition is associated with reduced renal loss of potassium. $^{43}$

\section{Lipid disorders}

In 1927 Joslin stated: "I believe the chief cause of premature development of atherosclerosis in diabetes, save for advancing age, is an excess of fat, an excess of fat in the body, an excess of fat in the diet, and an excess of fat in the blood". ${ }^{46}$ About three decades later,

Albrink reported that: "Hypertriglyceridaemia is the hyperlipidaemia par excellence of the diabetic". ${ }^{47}$

Diabetic dyslipidaemia is a cluster of plasma lipid and lipoprotein abnormalities that are metabolically interrelated. Hyperinsulinaemia in subjects with DM2, especially in those that have visceral obesity and fatty liver, has been linked to excessive flux of substrates for VLDL assembly and upregulation of the metabolic machinery for VLDL particles synthesis in the liver. ${ }^{48}$ In clinical practice, DM2 patients commonly present with reduced plasma high-density lipoprotein cholesterol (HDL-C), elevated small dense low density lipoprotein (sLDL-C) and raised triglyceride; ${ }^{49}$ a triad associated with significant atherogenic lipid profile. ${ }^{50}$ Increased atherosclerosis risks in DM patient is enhanced by the presence of small dense LDL particles in such patients. These particles are able to transverse the endothelium of blood vessels into the sub-endothelial space where they are retained by proteoglycans and oxidised, thus setting the stage for the development of diabetic cardiovascular complications. ${ }^{49}$

\section{Hypertension}

The pathogenesis of hypertension in DM involves genetic predisposition and a range of environmental and biological factors. These include unhealthy high salt diets, sedentary living, increased body sodium retention, visceral obesity, autonomic derangements, premature arterial stiffening, and endothelial dysfunction. $^{51}$ DM2 patients are more prone to hypertension and have increased propensity for ageadjusted cardiovascular death for any given systolic blood pressure. Some investigators suggest this maybe due to the absence of nocturnal BP dips in diabetics. Despite similar daytime office and home BP recordings, a "non-dipper" has a higher 24-hour and nocturnal BP values, with the latter in particular being a strong predictor of cardiovascular death. ${ }^{52}$ Data drawn from death certificates implicates hypertension in $44 \%$ of deaths among patients with diabetes mellitus. Therefore, hypertension is a key factor in the clinical evaluation of DM2 subjects and vice-versa.

As mentioned above, hyperinsulinaemia in DM2 worsen hypertension by stimulating subintimal smooth muscle and fibroblast proliferation. Furthermore, atherosclerosis in DM patients is accentuated by the negative impact of increased plasma insulin signaling on endothelial responses. ${ }^{53}$ The combination of increased mitogenesis, elevated exchangeable sodium and sympathetic activity, endothelial dysfunction and dyslipidaemia, due to hyperinsulinaemia increases CVD risks including hypertension in DM2 subjects.

\section{Ethnic susceptibility to increased kidney dysfunction}

It is known that there isincreased risk of renal disease in DM and metabolic syndrome patients. The pathogenic mechanisms implicated in this include increased glomerular hyperfiltration and enhanced proximal sodium reabsorption. ${ }^{54}$ Increased proximal tubular reabsorption of sodium seen in affected patients triggers glomerular hyperfiltration. ${ }^{55}$ Renal hyperfiltration in DM is associated with accelerated loss of kidney function and hypertension. ${ }^{54}$ Another contributor to renal dysfunction in DM2 is stimulation of the renin-angiotensin-aldosterone system (RAAS) ${ }^{56}$ Some investigators ${ }^{57}$ believe that activation of the RAAS is a primary event in the development of hypertension in affected patients. Attenuation of activated RAAS has been shown to slow down the 
progression of microvascular and macrovascular complications in patients with DM2. Thus, this system has become a target of interest in clinical management of diabetic patients, and this should be an area of concern in the management of Nigerian DM2 patients. Importantly, the high prevalence of glomerular hyperfiltration and enhanced proximal tubular reabsorption of sodium has been particularly reported in persons of African descent who have impaired fasting glycaemia or DM2. ${ }^{55}$ Another significant finding in those with African ancestry is higher prevalence of impaired renal autoregulation. ${ }^{58}$ These defects add up to cause increased chance of developing progressive glomerulosclerosis in blacks, even with modest blood pressure elevation. Therefore, it is important that there should be strict clinical monitoring and management of blood pressure in diabetics, especially in African diabetics. ${ }^{58}$ as they are more prone to hypertension and kidney dysfunction.

\section{Altered sympathetic nervous system}

In addition to the factors discussed above, increased activity of the sympathetic nervous system (SNS) is a mediator of hypertension in DM2. This occurs via increased stimulation of renal sodium reabsorption, increase in blood volume and cardiac output. ${ }^{59,60}$ In the Normative Ageing Study, elevated insulin level in obesity was associated with increased $\mathrm{SNS}^{61}{ }^{61}$ and these factors have also been reported in the development of hypertension. ${ }^{62}$ Therefore, early interventions targeted at disordered renal autoregulation, activation of RAAS in obese African patients with impaired glucose tolerance/DM2 ${ }^{57,58}$ and increased SNS activity ${ }^{62}$ could be beneficial in the clinical management of black DM2 patients. Such pathophysiological targeted approaches will help to mitigate macrovascular complications (coronary artery disease, stroke, and peripheral arterial disease) and microvascular complications (diabetic neuropathy, nephropathy, and retinopathy) in DM2 subjects.

\section{Disorders of infertility}

Some investigators have associated observed decrease in fecundity in modern societies to $\mathrm{DM} 2^{63}$ and its associated metabolic dysfunctions. ${ }^{64}$ The impact of DM on fertility affects both males and females but more sothewomen. ${ }^{64}$ One study found that compared with non-diabetics, couples in which the men were diabetic were three times more likely to seek treatment for infertility. Another study noted that despite similar fertilization rates and embryo quality among diabetic and non-diabetic unions, pregnancy rates were lower in couples with a diabetic male. ${ }^{65}$ Other factors associated with diabetic male infertility are erectile dysfunction, retrograde ejaculation, decreased libido and impotence. ${ }^{66}$ Other biochemical changes in male DM patients include higher concentrations of spermatozoa with disrupted transmembrane mitochondrial potential, activated caspase 3, reactive oxygen species as well as fragmented nuclear and mitochondrial sperm DNA. ${ }^{67}$ Further molecular perturbations by DM on spermatogenesis include subtle but vital changes including increased sperm DNA damage which has been implicated in poor embryo quality and implantation, in assisted reproductive therapy (ART). The above defect is associated with increase in the number of miscarriages. ${ }^{65}$ Hence, it is advisable to rule out glucose intolerance and DM2 in infertile couples, especially among male partners. It is important that the above factors are considered in patients undergoing ART.

\section{Bone disorders}

The relationship between diabetes and bone disease is non-linear, as the effect of DM1 and DM2 on bones are different. While the bone mineral density (BMD) is consistently low in DM1, it is similar in nondiabetic and DM2 subjects. Nevertheless, both forms of diabetes are associated with an increased risk of bone fracture. ${ }^{68}$ Studies have shown that the risk of hip fracture in DM2 patients is increased by 1.7-fold, compared with non-diabetic controls, despite nondiminished bone mineral density (BMD) in the patients. In addition, vertebral fracture risk of DM2 patients is increased compared to healthy nondiabetics. Some researchers have interpreted this to mean that bone fragility in DM patients depends on bone quality deterioration rather than bone mass reduction. ${ }^{69,70,71}$ The mechanisms responsible for the impact of DM2 on bone integrity include increased urinary excretion coupled with lower intestinal absorption of calcium, inappropriate homeostatic response to parathyroid hormone secretion, alteration of vitamin D regulation, increased insulin and IGF-1 concentrations, accumulation of end products of glycation on bone tissue. ${ }^{68,71}$ 


\section{Diabetic neuropathy}

Diabetic neuropathy (DN) is the commonest complication of diabetes mellitus and a source of significant morbidity and mortality in affected patients. It is a microvascular complication defined by the presence of symptoms and/or clinical signs of altered nerve conduction after exclusion of other causes of neuropathy. The global prevalence of DN is up to $65 \%,{ }^{72}$ but in Nigeria it was reported $59.2 \%{ }^{19}$ and $69 \%$ in Mexico. ${ }^{73}$ The microvascular complications underlying DN make diabetic patients 15 times more prone to lower limbs amputation compared to the general population. ${ }^{74}$ Clinical significance of DN was captured in a study that reported it being implicated in $50-75 \%$ of nontraumatic amputations. ${ }^{75}$

Peripheral DN is associated with peripheral nerves myelin damage and decrease in nerve conduction velocity. ${ }^{74}$ The myelin sheath is a multilayered membrane produced in the peripheral nervous system by differentiation of the plasma membrane of Schwann cells. The function of the myelin membrane is to allow efficient transmission of nerve impulses along the axons. A major biochemical difference between myelin and other biological membranes is its high lipid-to-protein ratio. An isolated myelin sheath is made up of $70-80 \%$ lipids and $20-30 \%$ proteins. $^{76}$ The syndromes affecting peripheral nerves can be separated into quickly reversible manifestations and chronic progressive syndromes. The chronic progressive syndromes of DN manifest as symmetric polyneuropathies and focal or multifocal neuropathies.

${ }^{74} \mathrm{DN}$ is an insidious disease which in clinical practice presents as apparition of pains in the lower limbs and plantar ulcers. The complication of DN is initiated by hyperglycaemia and associated metabolic abnormalities in long standing diabetic disease. ${ }^{74}$ The Diabetes Control and Complications Trial studies confirmed this when it showed that intensive insulin treatment reduced the development and progression of diabetic neuropathy. ${ }^{77}$ It is known that reduced or abnormal fatty acid synthesis plays an important role in altered myelin lipid and protein composition. This alteration in myelin affects membrane fluidity and function, ultimately contributing to the pathogenesis of DN. ${ }^{78}$ In support of the above, gamma-linoleic acid (GLA) supplementations showed promise in reducing the symptoms of DN in a study reported over two decades ago. ${ }^{79}$ The early observation by Keen and coworkers in $1993^{79}$ is significant because despite control of risk factors of macrovascular and microvascular diseases (blood pressure, lipids and blood glucose levels) DN complications still occur. ${ }^{80}$ Therefore, it is important that targeted therapies to the underlying mechanisms of DN should be further investigated and instituted in the management of affected patients.

\section{Dementia}

Cardiovascular risk factors including DM, hypertension and hyperlipidaemia are associated with dementia. ${ }^{81}$ As the prevalence of DM increases, there is a concomitant rise in the level of dementia ${ }^{82}$ and this will have significant implication for developing economies like Nigeria where increase in DM2 prevalence is now a cause for concern. ${ }^{18}$ The World Alzheimer Report of 2015 states that over 46 million people live with dementia worldwide, and that this number is estimated to increase to 131.5 million by 2050 with most of the increase occurring in low income (264\%), middle income (223\%) and upper middle income $(227 \%)$, countries. ${ }^{83}$ Population based studies shows that DM2 patients have a twofold increased risk of developing either vascular dementia or Alzheimer's disease. ${ }^{84}$ Another recent population based study concluded that the hyperglycaemia of DM and not its association with hypertension or hyperlipidaemia is the main driver of dementia. ${ }^{82}$ The association between DM2 and dementia has also been demonstrated in Nigeria. ${ }^{85,86}$

Dementia is a common cause of morbidity in late stages of diabetes mellitus and it is one of the commonest and most disabling late life mental disorders. ${ }^{87}$ The pathogenic mechanisms linked to dementia in DM2 subjects are hyperinsulinaemia, brain infarcts, white matter disease, advanced glycosylated end products, and lipoprotein related proteins. ${ }^{88}$ Furthermore, poor glycemic control and chronic episodes of hypo- or hyperglycemia have been linked to microangiopathy, neuronal loss, and cognitive impairment in diabetic states. ${ }^{89}$ This emphasizes the need for quality management of DM2 so as to reduce the risk of dementia.

The disease complication is associated with huge economic burden with current global cost estimate put at US $\$ 818$ billion. The projection in 2015 was that this cost could reach a trillion dollar by this year. ${ }^{83}$ This huge cost occasioned by the management of dementia cannot be afforded by most developing countries, especially by those in sub-Saharan Africa. 
Little wonder that about $94 \%$ of people living with dementia in low and middle income countries are cared for at home. ${ }^{83} \mathrm{~A}$ more sustainable program for mitigating dementia and other complications of DM2 in developing countries like Nigeria will involve efficient public and clinical management of the disease. ${ }^{18}$

\section{Conclusion}

The high prevalence of diabetic complications in Nigerian patients is associated with poor glycaemic control. This can be improved by a more integrated care model earlier suggested by Zimmet and coworkers in 2014. ${ }^{16}$ This approach when combined with better understanding of the metabolic derangements of the DM2, especially in the recognition of increased susceptibility of Africans to some diseases, could help to improve quality of care offered to Nigerian diabetics.

\section{Take home messages}

1. The prevalence of DM 2 is rising in Nigeria and so are the complications of the disease.

2. Diabetic patients of Africa origin including Nigerians are more susceptible to certain disease complications, and these should be noted in clinical evaluations.

3. Improved understanding of DM2 biology and relevant metabolic consequences will help patients' management and outcomes.

3. The poor level of glycaemia may be improved by improved use of $\mathrm{HbA1c}$.

\section{References}

1. Diagnosis and Classification of Diabetes Mellitus. American Diabetes Association. Diabetes Care.2014; 37(Suppl. 1).

2. $7^{\text {th }}$ Edition, International Diabetes Federation Report, 2015.

3. Trends in obesity and diabetes across regions in Africa from 1980 to 2014: a pooled analysis of population-based studies. NCD Risk Factor Collection (NCD-RisC) Africa Working Group.Int J Epidemiol 2017, 1-12. doi: 10.1093/ije/dyx078

4. World Health Organization. Global health risks: mortality and burden of disease attributable to selected major risks Geneva.WHO,https://www.who.int/healthinfo/global_bur den_disease/; 2009. [accessed 12 April 2012]

5. Oghagbon EK, Giménez-Llort L. Sustaining Increase in Life Expectancy in Africa Requires Active Preventive
Measures against Non-Communicable Diseases.Open J Prev Med. 2014;4: 283-292.

6. Escobedo-de la Pena J, Buitron-Granados LV, RamirezMartinez JC, Chavira-Mejia R, Schargrodsky $\mathrm{H}$, Champagne BM. Diabetes in Mexico. CARMELA Study. Cir. 2011; 79: 394-401.

7. International Diabetes Federation, www.idf.org/webdata/docs/; 2001.[accessed 18 September 2014].

8. Adeghate $E^{1}$, Schattner P, Dunn E. An update on the etiology and epidemiology of diabetes mellitus.Ann N Y Acad Sci. 2006; 1084: 1-29.

9. Zimmet, P. The pathogenesis and prevention of diabetes in adults.Genes, autoimmunity, and demography.Diabetes Care.1995; 18: 1050-1064.

10. King, H., Aubert, R. \& Herman, W. Global burden of diabetes, 1995-2025. Prevalence, numerical estimates and projections. Diabetes Care.1998; 21: 1414-1431.

11. Wild S, Roglic G, Green A, Sicree R, King H. Global Prevalence of Diabetes: Estimates for the year 2000 and projections for 2030. Diabetes Care.2004; 27: 1047-1053.

12. Africa at a glance. International Diabetes Federation (IDF) Atlas, $6^{\text {th }} \quad$ Edition,https://www.idf.org/regions/africa; 2013. [accessed $1^{\text {st }}$ April, 2017]

13. Mattei J, Malik V, Wedick NM, Hu FB, Spiegelman D, Willet WC et al. Reducing the global burden of type 2 diabetes by improving the quality of staple foods: The Global Nutrition and Epidemiologic Transition Initiative.Global Health.2015; 11: 23.

14. Nicholson G, Hall GM. Diabetes mellitus: new drugs for a new epidemic. Br J Anaesthesia.2011; 107: 65-73.

15. Wahl S, Drong A, Lehne B, Loh M, Scott WR, Kunze S et al. Epigenome-wide association study of body mass index, and the adverse outcomes of adiposity. Nature.2017; 541: 81-86.

16. Zimmet PZ, Magliano D, Herman WH, Shaw JE. Diabetes: $21^{\text {st }}$ century challenge. Lancet Diabetes Endocrinol.2014; 2: 56-64.

17. International Diabetes Federation, https://www.idf.org/membership/afr/nigeria;2014.[accesse d $23^{\text {rd }}$ November 2015]

18. Oghagbon EK. Improving persistently elevated $\mathrm{HbA} 1 \mathrm{c}$ in diabetes mellitus patients in Nigeria.Ethn Dis. 2014; 24[4]: 502-507

19. Chinenye S, UlokoAE,Ogbera AO, Ofoegbu EN, Fasanmade OA, Fasanmade AA et al. Profile of Nigerians with diabetes mellitus - Diabcare Nigeria study group (2008): Results of a multicenter study. Indian J EndocrinolMetab. 2012; 16(4): 558-564

20. Edo AE, Akhuemokhan K. Relationships between haemoglobin $\mathrm{A}_{1 \mathrm{c}}$ and spot glucose measurements in Nigerians with type 2 diabetes mellitus. Nig J ClinPract. 2012; 15(1): 23-26.

21. Erasmus RT, Alanamu RA, Bojuwoye B, Oluboyo P, Arije A. Diabetic retinopathy in Nigerians: relation to duration of diabetes, type of treatment and degree of control. East Afr Med J. 1989; 66: 248-254

22. Rotimi C, Daniel H, Zhou J et al. Prevalence and determinants of diabetic retinopathy and cataracts West 
Africa type II diabetes patients. Ethn Dis. 2003; 13(Suppl.2): S110-S117

23. Ashaye A, Arije A, Kuti M et al. Retinopathy among type 2 diabetic patients seen at a tertiary hospital in Nigeria: a preliminary report. ClinOphthalmol. Mar 2008; 2(1): 103108

24. Kalk WJ. Joannou J. Ntsepo S, Mahomed I, Mahanlal P, Becker PJ. Ethnic differences in the clinical and laboratory associations with diabetic retinopathy: Studies in patients in patients of African, European and Indian origins. J Int Med. 1997; 241: 31-37

25. Ogbera AO, Chineneye S, Onyekwere A, Fasanmade O. Prognostic Indices of DM mortality. Ethn Dis. 2007, 17(4):721-725.

26. Akanji AO, Adetuyibi A. The pattern of presentation of foot lesions in Nigerian diabetic patients. West Afr J Med. 1990; 9: 1-5

27. Adebisi SA, Oghagbon EK, Jimoh AK. Glycated haemoglobin and associated variables in diabetics: Ilorin experience West Afr J Med. 2003; 22(4): 318-320.

28. Stratton IM, Kohner EM, Aldington SJ et al., Turner RC, Holman RR, Manley SE, Matthews DR.: UKPDS 50: risk factors for incidence and progression of retinopathy in type 2 diabetes over 6 years from diagnosis. Diabetologia. 2001; 44: 156-163

29. Vishwanath K, McGavin DD. Diabetic retinopathy: clinical findings and management. Community Eye Health. 2003; 16: 21-24

30. Agaba EI. Characteristics of type 2 diabetics presenting with end stage renal disease at the Jos University Teaching Hospital, Nigeria. West Afr J Med. 2004; 23: $142-145$

31. Katusi'c D, Tomi'c M, Juki'c T et al. Obesity-a risk factor for diabetic retinopathy in type 2 diabetes? CollAntropol. 2005; 29(Suppl 1): 47-50

32. Kolawole BA, Ajayi AA. Prognostic indices for intrahospital mortality in Nigerian diabetic NIDDM patients.Role of gender and hypertension. J Diabetes Complications. 2000; 14(2): 84-89

33. Jisieike-Onuigbo NN, Unuigbe EI, Kalu OA, Oguejiofor $\mathrm{CO}$, Onuigbo PC. Prevalence of dyslipidemia among adult diabetic patients with overt diabetic nephropathy in Anambra state South-East Nigeria.NJCP. 2011; 14 (2): 171-175

34. Odili VU, Oghagbon EK, Ugwa NA, Ochei UM, Aghomo OE.Adherence to international guidelines in the management of hypertension in a tertiary hospital in Nigeria.Tropical Journal of Pharmaceutical Research. 2008; 7(2): 945-952

35. Adebisi SA, Oghagbon EK, Okesina AB. Management of obesity in diabetic patients. Diabetes International. 2003; 12: 61-65

36. Hovens MMC, Van de Laar FA, Cannegieter SC, Vandenbroucke JP.Acetylsalicylic acid (Aspirin) for primary prevention of cardiovascular disease in type 2 Diabetes Mellitus. (protocol) Cochrane Database of Systematic Reviews 2005, Issue 3. Art. No.: CD005446.

37. Sadler JBA, Bryant NJ, Gould GW, Welburn CR. Post translational modifications of GLUT-4 affects its subcellular localization and translocation. Int J Mol Sci. 2013; 14: 9963-9978.

38. DeFronzo RA, Tripathy D. Skeletal muscle insulin resistance is the primary defect in type 2 diabetes.Diabetes Care. 2009; 32: S157-S163.

39. Steven S, Taylor R. Restoring normoglycaemia by use of a very low calorie diet in long and short duration type 2 diabetes. Diabet Med. 2015; 32: 1149 - 1155.

40. Cecilia C, Wang L, Gurevich I, Draznin B. Insulin affects smooth muscle cell phenotypes and migration via distinct signaling pathways. Diabetes.2003; 52: 2562-2569.

41. Lago MR, Singh PP, Nesto RW. Diabetes and hypertension. Nat ClinPractEndocrinolMetab. 2007; 3(10): 667.

42. Liamis G, Rodenburg EM, Hoffman A, Zietse R, Stricker BH, Hoorn EJ et al.Electrolyte Disorders in community subjects: prevalence and risk factors. Am J Med. 2013; 126: 256-263.

43. Liamis G, Liberopoulos E, Barkas F, Elisaf M. Diabetes mellitus and electrolyte disorders.World J Clin Cases. 2014; 2(10): 488-496.

44. Liamis G, Milionis HJ, Elisaf M. Hyponatremia in patients with infectious diseases. J Infect. 2011; 63(5): 327-335.

45. Yang L, Frindt G, Palmer LG. Magnesium modulates ROMK channel-mediated potassium secretion. J Am SocNephrol. 2010; 21: 2109-2116.

46. Joslin E. Arteriosclerosis and diabetes. Ann Clin Med 1927; 5: 1061-79.

47. Allbrink M, May E. Serum triglycerides in health and diabetes. Diabetes.1958; 7: 154.

48. Taskinen MR. Type 2 diabetes as a lipid disorder.CurrMol Med. 2005; 5(3): 297-308.

49. Aslan I, Kucksayan E, Aslan M. Effects of insulin analog initiation therapy on LDL/HDL subfraction profile and HDL associated enzymes in type 2 diabetic patients. Lipids Health Dis. 2013; 12: 54.

50. Vann J, Pan J, Charles MA, Krauss R, Wong N, Wu X. Atherogenic lipid phenotype in a general group of subjects. Arch Pathol Lab Med. 2007; 131(11): 1679-1685

51. James PA, Oparil S, Carter BL, Cushman WC, DennisonHimmelfarb C, Handler J et al. Evidence-Based Guideline for the Management of High Blood Pressure in Adults: Report from the Panel Members Appointed to the Eighth Joint National Committee (JNC 8). JAMA. 2014; 311(5): 507-520.

52. Dolan E,Stanton A, Thijs L, Hinedi K, Atkins N, McClory S. Superiority of ambulatory over clinic blood pressure measurement in predicting mortality: the Dublin outcome Study. Hypertension. 2005; 46(1): 156-161.

53. Zhang H, Dellsperger KC, Zhang C. The link between metabolic abnormalities and endothelial dysfunction in type 2 diabetes: an update. Basic Res Cardiol.2011; 107: 237.

54. Strazzullo P, Barbato A, Galletti F, Barba G, Alfonso S, Roberto I et al. Abnormalities of renal sodium handling in the metabolic syndrome. Results of the Olivetti Heart Study. J Hypertens.2006; 24: 1633-1639. 
55. Pruijm M, Wuerzner G, Maillard M, Bovet P, Renaud C, Bochud $\mathrm{M}$ et al. Glomerular hyperfiltration and increased sodium reabsorbtion in subjects with type 2 diabetes or impaired glucose in a population of the African region. Nephrol Dial Transplant.2010; 25: 2225-2231.

56. Matayoshi T, Kamide K, Takiuchi S, Horio T, Yoshihara F, Nakamura $\mathrm{S}$ et al. Relationship between insulin resistance and the renin-angiotensin system: analysis for patients with essential and renovascular hypertension. ClinExpHypertens. 2007; 29: 479-487.

57. Hsueh WA, Wyne K. Renin-Angiotensin-Aldosterone System in Diabetes and Hypertension. J ClinHypertens (Greenwich). 2011; 13: 224-237.

58. Burke M, Pabbidi MR, Farley J, Roman RJ. Molecular mechanisms of renal blood autoregulation.CurrVascPharmacol. 2014; 12(6): 845-858.

59. Sowers JR, Epstein M, Frohlich ED. Diabetes, hypertension, and cardiovascular disease: an update. Hypertension 2001; 37(4): 1053-1059.

60. Castro JP, El-Atat FA, McFarlane SI, Aneja A, Sowers JR: Cardiometabolic syndrome: pathophysiology and treatment. CurrHypertens Rep. 2003; 5: 393- 401.

61. Ward KD, Sparrow D, Landsberg L, Young JB, Weiss ST: The influence of obesity, insulin, and sympathetic nervous system activity on blood pressure. Clin Res. 1993; 41: 168A.

62. Masuo K, Katsuya T, Fu Y, Rakugi H, Ogihara T, Tuck ML et al. Beta2- and beta3- adrenoceptor polymorphisms are related to the onset of weight gain and blood pressure elevation over 5 years. Circulation.2005; 111; 3429-3434.

63. Hamilton BE, Ventura SJ. Fertility and abortion rates in the United States, 1960-2002.Int. J Androl.2006; 29: 3445.

64. Tobias DK, Hu FB, Missmer SA, Manson JE, Chavarro J. History of Infertility and Risk of Type 2 Diabetes Mellitus in Women. Circulation. 2013; 127: AMP91.

65. Mulholland J, Mallidis C, Agbaje I, McClure N. Male diabetes mellitus and assisted reproduction treatment outcome. Reprod Biomed Online. 2011; 22 (2): 215-219.

66. Fedele D. Therapy insight: sexual and bladder dysfunction associated with diabetes mellitus. Nat ClinPract Urol. 2005; 2: 282-290.

67. Alves MG, Martins AD, Rato L, Moreira PI, Socorro S, Oliveira PF. Molecular mechanisms beyond glucose transport in diabetes-related male infertility. BiochimicaetBiophysicaActa. 2013; 1832: 626-635

68. Isidro ML, Ruano B. Bone disease in diabetes.Curr Diabetes Rev. 2010; 6(3): 144- 155.

69. Yamaguchi T, Sugimoto T. Bone metabolism and fracture risk in type 2 diabetes mellitus.

Bone KEy Reports (2012) 1, Article number: 36.

70. Okazaki R. Diabetes Mellitus and bone metabolism. Clin Calcium. 2011; 21(5): 669- 675.

71. Carnevale V, Romagnoli E, D'Erasmo E. Skeletal involvement in patients with diabetes mellitus.Diabetes Metab Res Rev. 2004; 20(3): 196-204.

72. Arora N, Niraj G. Management of painful peripheral neuropathy. BJMP. 2013; 6: a606.
73. Ibarra CT, Rocha Jde J, Hernández RO, Nieves RE, Leyva RJ. Prevalence of peripheral neuropathy among primary care type 2 diabetic patients. Rev Med Chil.2012;140: 1126-1131.

74. Coste TC, Gerbi A, Vague P, Maixent J-M, Pieroni G, Raccah D. Peripheral diabetic neuropathy and polyunsaturated fattyacid supplementations: natural sources or biotechnological needs? Cell Mol Biol. 2004; 50(7): 845-853.

75. Vinik AI, Park TS, Stansberry KB, Pittenger GL. Diabetic neuropathies.

76. Garbay B, Heape AM, Sargueil F, Cassagne C. Myelin synthesis in the peripheral nervous system. ProgNeurobiol. 2000; 61: 267-304.

77. The DCCT Research Group, The effect of intensive diabetes therapy on the development and progression of neuropathy. Ann Intern Med. 1995; 122: 561-568.

78. Verheijen MH, Camargo N, Verdier V, Nadra K, de Preux Charles AS, Medard JJ et al. SCAP is required for timely and proper myelin membrane synthesis. ProcNatlAcadSci USA. 2009; 106: 21383-21388.

79. Keen H, Payan J, Allawi J, Walker J, Jamal GA, Weir A et al. Treatment of diabetic neuropathy with $\gamma$-linolenic acid. Diabetes Care.1993; 16: 8-15.

80. Kles KA, Vinik AI. Pathophysiology and treatment of diabetic peripheral neuropathy: the case for diabetic neurovascular function as an essential component. Curr Diabetes Rev. 2006; 2(2):131-45.

81. de Winter CF, Bastiaanse LP, Hilgenkamp TI, Evenhuis HM, Echteld MA. Cardiovascular risk factors (diabetes, hypertension, hypercholesterolaemia and metabolic syndrome) in older people with intellectual disability: results of the HA-ID study. Res DevDisabil. 2012; 33: 1722-1731

82. Fan Y-C, Hsu J-L, Tung H-Y, Chou C-C, Bai C-H. Increased dementia risk predominantly in diabetes mellitus rather in hypertension or hyperlipidaemia: a population based study. Alzheimer's Research \& Therapy.2017; 9: 7.

83. World Alzheimer Report 2015, The Global Impact of Dementia, An analysis of prevalence, incidence, cost and trends, Alzheimer's Disease International, 2015.

84. Stewart $\mathrm{R}$ et al. Type 2 diabetes mellitus, cognitive impairment and dementia.Diabet Med. 1999; 16: 93-112

85. Eze $\mathrm{CO}$ et al. The Prevalence of Cognitive Impairment Amongst Type 2 Diabetes Mellitus Patients at Abakaliki South-East Nigeria. J Diabetes MetabSyndrDisord.2015; 1:1.

86. Ugoya $\mathrm{SO}$ et al. Cognitive Dysfunction in Diabetes Mellitus in Jos, North-Central Nigeria. Hungary Med J. 2008; 2(2): 215-219.

87. Harati Y. Diabetes and the nervous system. Endocrinol.Metab.Clin. North Am. 1996; 25: 325-359

88. Luchsinger JA. Type 2 diabetes and cognitive impairment: linking mechanisms. J Alzheimers Dis. 2012; 30: 185-198.

89. Roberts RO et al. Association of duration and severity of diabetes mellitus with mild cognitive impairment.Arch Neurol. 2008; 65: 1066-1073. 